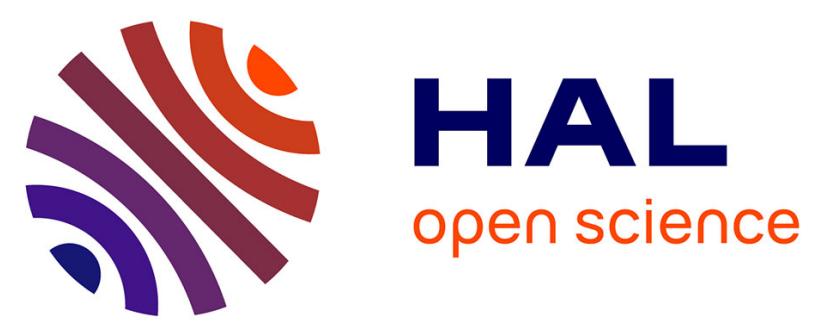

\title{
Model-based decision support methods applied to the conservation of musical instruments: application to an antique cello
}

Romain Viala, Vincent Placet, Sandie Le Conte, Stéphane Vaiedelich, Scott Cogan

\section{To cite this version:}

Romain Viala, Vincent Placet, Sandie Le Conte, Stéphane Vaiedelich, Scott Cogan. Model-based decision support methods applied to the conservation of musical instruments: application to an antique cello. 37th Conference and Exposition on Structural Dynamics, Jan 2019, Orlando, FL, United States. pp.223-227, 10.1007/978-3-030-12075-7_25 . hal-02370580

\section{HAL Id: hal-02370580 \\ https://hal.science/hal-02370580}

Submitted on 26 Nov 2020

HAL is a multi-disciplinary open access archive for the deposit and dissemination of scientific research documents, whether they are published or not. The documents may come from teaching and research institutions in France or abroad, or from public or private research centers.
L'archive ouverte pluridisciplinaire HAL, est destinée au dépôt et à la diffusion de documents scientifiques de niveau recherche, publiés ou non, émanant des établissements d'enseignement et de recherche français ou étrangers, des laboratoires publics ou privés.

\section{(c)(1)}

Distributed under a Creative Commons Attribution| 4.0 International License 


\title{
Model-based Decision Support Methods Applied to the Conservation of Musical Instruments: Application to an Antique Cello
}

\author{
VIALA R. ${ }^{1}$, PLACET V. ${ }^{1}$, LE CONTE S. ${ }^{2-3}$, VAIEDELICH S. ${ }^{2-3}$ and COGAN S. ${ }^{1}$ \\ ${ }^{1}$ Univ. Bourgogne-Franche-Comté, FEMTO-ST institute, CNRS/UFC/ENSMM/UTBM, Department of \\ applied Mechanics, 25000 Besançon-FR \\ ${ }^{2}$ Equipe Conservation Recherche. Musée de la musique, Paris, France
}

\begin{abstract}
3 Centre de Recherche sur la Conservation (CRC), Muséum national d'Histoire naturelle, CNRS, Ministère de la Culture, 36 rue Geoffroy Saint Hilaire, 75005 Paris, France.
\end{abstract}

\begin{abstract}
In musical instrument making and restoration domains, the variability of the materials and the irreversibility of the changes are issues for the experimental study of the impact of design changes and restorations on musical instruments. In addition, the analytical methods based on simplified geometries and models are not sufficiently detailed for the study of complex structures and phenomena. The virtual prototyping, and its different capabilities, can be a powerful method for instrument makers and museum curators as a decision support tool. Nevertheless, the accuracy of the model is an important matter to assess good predictions. In the case of antique and unique instruments, it is sometimes hard to obtain exhaustive geometrical properties. Similarly, it is also difficult to evaluate the material properties of full instruments, and this uncertainty may have a strong impact on the output features of the numerical models. In this study, a numerical model of cello is developed using finite element method. It is used to evaluate the impact of a modification of a geometrical property on dynamical features. It is shown that the lack of knowledge on the arching height of the top and back plates of a cello has a strong impact on the computed dynamical properties of the cello. Secondly, the model is considered with and without repair wedges and defects like galleries excavated by wood-boring insects. It is observed that the bridge admittance exhibits discrepancies above $220 \mathrm{~Hz}$ which is in the low frequencies domain of the model and quantify the impact of repairs. This model capability is a starting point for further simulations accounting for material and geometrical uncertainties and to assess the confidence level of a model for restoration issues.
\end{abstract}

Keywords: Musical acoustics, virtual prototyping, dynamical modelling, cultural heritage conservation, finite element model.

\section{INTRODUCTION}

Generally applied in industrial and research domains, model-based decision support has been used for decades as a powerful tool. Considering uncertainties and finely modeled geometries, it can be used for the virtual prototyping of parts and structures. In the musical instrument domain, these methods can be used as a support for the design of new instruments. Moreover, it can also be used for the conservation and restoration of antique and valuable instruments. Many models of musical instruments have been developed for decades, especially violins since the 1980's [1]. More recently, models have been developed for the reverse engineering of a violin [2] or the study of dynamics and acoustics of violin body [3] and the way geometric properties interacts. Models have also been developed to screen material properties of the wooden constituents of the violin [4] and as a decision support tool for violins and guitars [5].

It must be highlighted that curators deal with unique and irreplaceable instruments, which represents a main difference with usual industrial products, for which the critical aspects mostly deal with security and cost concerns. Musical instruments are 
made with different pieces of wood whose mechanical properties may be hard to evaluate and represent a considerable lack of knowledge. In the same manner, the fine knowledge of the geometry can be either impossible or costly, involving experiments and devices [6], [7].

So, a major concern must be pointed out about the geometrical and material uncertainties, and the way they can affect the results of a model. Moreover, the climatic conditions that an instrument can undergo have to be considered for such problematics, as musical instruments constantly undergo relative humidity and temperature changes when outside the showcase [8]. In this study, a cello is modeled using the finite element method, and a geometrical characteristic is changed, the height of the top and back plates, while the material properties are unchanged. Secondly, the impact of repairs and defaults on the dynamical response of the model is evaluated, as a potential starting point for a decision support tool for restoration of musical instruments. The object of study of this work is an antique cello which exhibits many previously repaired cracks, and galleries produced by xylophagous insects, whose activity can be experimentally detected by acoustic emission [9].

The cello is made of different species of wood: spruce, maple, ebony and sometimes rosewood that are assembled together. Different experimental studies in the dynamical fields have been focused on several parts of the cello, such as the tailpiece dynamics [10], [11] and studied wolf notes [12]. The body of the instrument is here the main object of concern and is made of carved maple back and bent sides, and a carved spruce soundboard. The aim of the study is to evaluate the impact of an incorrect geometrical modeling on the dynamical response. For this purpose, the geometry of the cello is finely modeled using computer aided design and the finite element method, described below.

\section{ANALYSIS}

The studied structure is a cello, made by Pietro Guarneri in the $18^{\text {th }}$ century and kept at the musée de la musique, Paris, under the label E.1555. The nominal model is made using the template of a model given in [13] and the data collected by curators and instrument makers about some properties of the E1555 cello. The Computer aided design (CAD) of the cello model has been made using the software SOLIDWORKS and is shown in the figure 1.

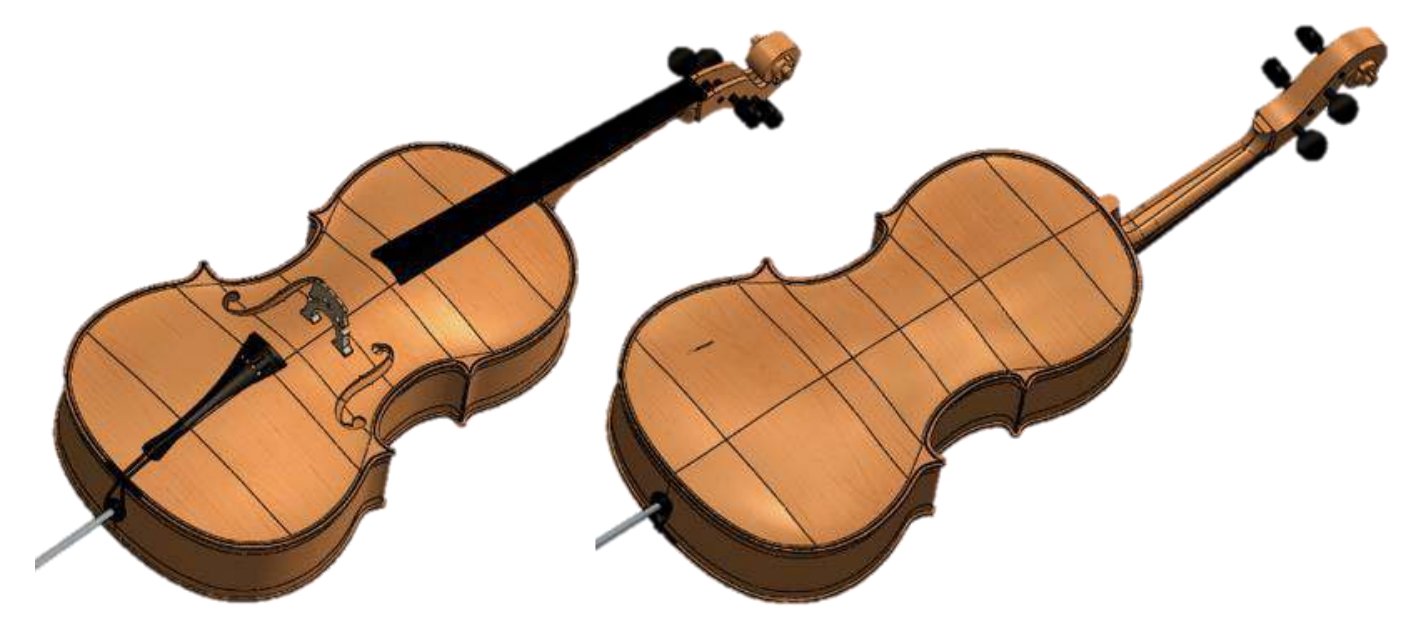

Figure 1: Computer aided design, (CAD) of the cello model; left: front view, right: back view

The repair wedges and galleries are schematized in the figure 2 . The geometry has been meshed with tetrahedral elements with quadratic interpolation, the number of nodes is approximately equal to 350000, which leads to a value close to 1 million degrees of freedom. Most of the parts are made of wood (maple, spruce an ebony species). The wooden parts are modelled under the linear elastic hypothesis, with an orthotropic definition of the elastic parameters. The material properties identified are taken from [14] and [15] and given in the table 1. For the latter, three models will be considered: the first model made with nominal values obtained in [13], labelled as V1 and the one with the correct arch height of both back and top, which corresponds to an increase of $10 \mathrm{~mm}$ and a corresponding global shape change, labelled as V2. The photogrammetry method has been used for 
the measurements of the arch dimensions. In addition, a model is created based on the model V2 without wedges and gallery, labelled as V2_2, to evaluate the impact of repairs or defaults on the behavior of the cello.

\begin{tabular}{|c|c|c|c|}
\hline & Maple & Spruce & Ebony \\
\hline Specific gravity [-] & 0.64 & 0.44 & 1.09 \\
\hline $\mathrm{E}_{L}[\mathrm{MPa}]$ & 12200 & 12840 & 18000 \\
\hline $\mathrm{E}_{\mathrm{R}}[\mathrm{MPa}]$ & 1820 & 1000 & 2450 \\
\hline $\mathrm{E}_{\mathrm{T}}[\mathrm{MPa}]$ & 1060 & 650 & 1520 \\
\hline $\mathbf{v}_{\mathrm{LR}}, \mathrm{v}_{\mathrm{RL}}[-]$ & $0.37,0.05$ & $0.37,0.03$ & $0.56,0.07$ \\
\hline $\mathbf{v}_{\mathrm{RT}}, \mathbf{v}_{\mathrm{TR}}[-]$ & $0.65,0.37$ & $0.48,0.3$ & $0.95,0.7$ \\
\hline $\mathbf{v}_{\mathrm{LT}}, \mathrm{v}_{\mathrm{TL}}[-]$ & $0.45,0.03$ & $0.4,0.02$ & $0.7,0.06$ \\
\hline $\mathbf{G}_{\mathrm{LR}}[\mathrm{MPa}]$ & 1375 & 810 & 1660 \\
\hline GRT [MPa] & 430 & 46 & 540 \\
\hline $\mathbf{G}_{\mathrm{TL}}[\mathrm{MPa}]$ & 1010 & 790 & 1300 \\
\hline
\end{tabular}

Table 1: Orthotropic material properties for maple, spruce and ebony species, taken from [14] and [15].

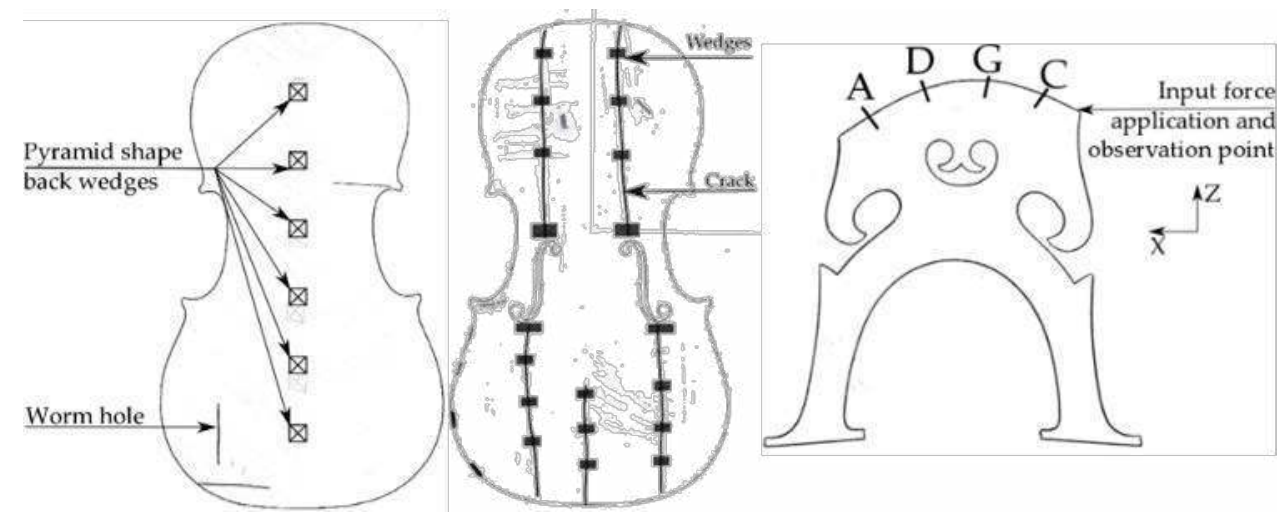

Figure 2: Left: scheme of the wedges and cracks of the cello, based on radiographs provided by the laboratory of the Musée de la musique, Paris, right: bridge excitation and measurement point and direction on a Belgian cello.

The bent parts orientation has been considered by changing the orientation of the local coordinate frames of the corresponding elements. The modal basis computation of 100 modes lasts one hour. Once the modes are computed, the comparison between each case is made with a modal assurance criterion, proposed in [16]. To highlight the capability of the finite element models, the bridge admittances of each case are computed. The admittance is computed with the application of an input force and an observation of either the displacement velocity and acceleration at the same point in the same direction, as shown in the figure 2 , right part. The bridge admittances are often considered as a signature of the soundboard musical instrument dynamics and has been widely measured [17] but never modeled previously on a numerical model of a cello. The synthesis of the admittance of a cello can unlock some issues that are common in experiments, such as the reproducibility of the measure [18] and the interpretation of the results in the case of geometrical and material differences between instruments, since numerical models can change each parameter at once.

\section{RESULTS}

The computed modal bases are rich and only low frequency canonical modes will be considered. These modes, labeled as T1, $\mathrm{C} 2, \mathrm{C} 3$ and C4 according to usual nomenclature [19], are shown in the figure 3 and the evolution of the eigenfrequencies for the corresponding modes for each model V1, V2 and V2_2 are given in the table 2. 
It is shown that changing the arch height can lead to a variation of the eigenfrequencies of up to $8 \%$ for low frequencies mode. In addition, for higher frequencies, the computed and experimental modal bases are not correlated above the $20^{\text {th }}$ modes which states for a completely different behavior above $250 \mathrm{~Hz}$. Thus, such geometrical parameters like arch heights and thickness are keys for the good correlation of a model and a real instrument and need to be characterized.

The admittances at the bridge for the cases V2 (without repairs) and V2_2 (without repairs) are given in the figure 4. First, the usual A0 acoustic mode is not displayed on the admittance since the fluid-structure interaction was not implemented in the model. The admittance shape below $230 \mathrm{~Hz}$ is like the one given in [19] (with lower frequencies) and, under this point, no significative differences are shown between the repaired and not repaired cases. Above this frequency, differences occur in the admittances' shapes, and increase with increasing frequencies, which highlights the facts that repairs affect the dynamical behavior of the cello, even in the low and mid-frequency domains.

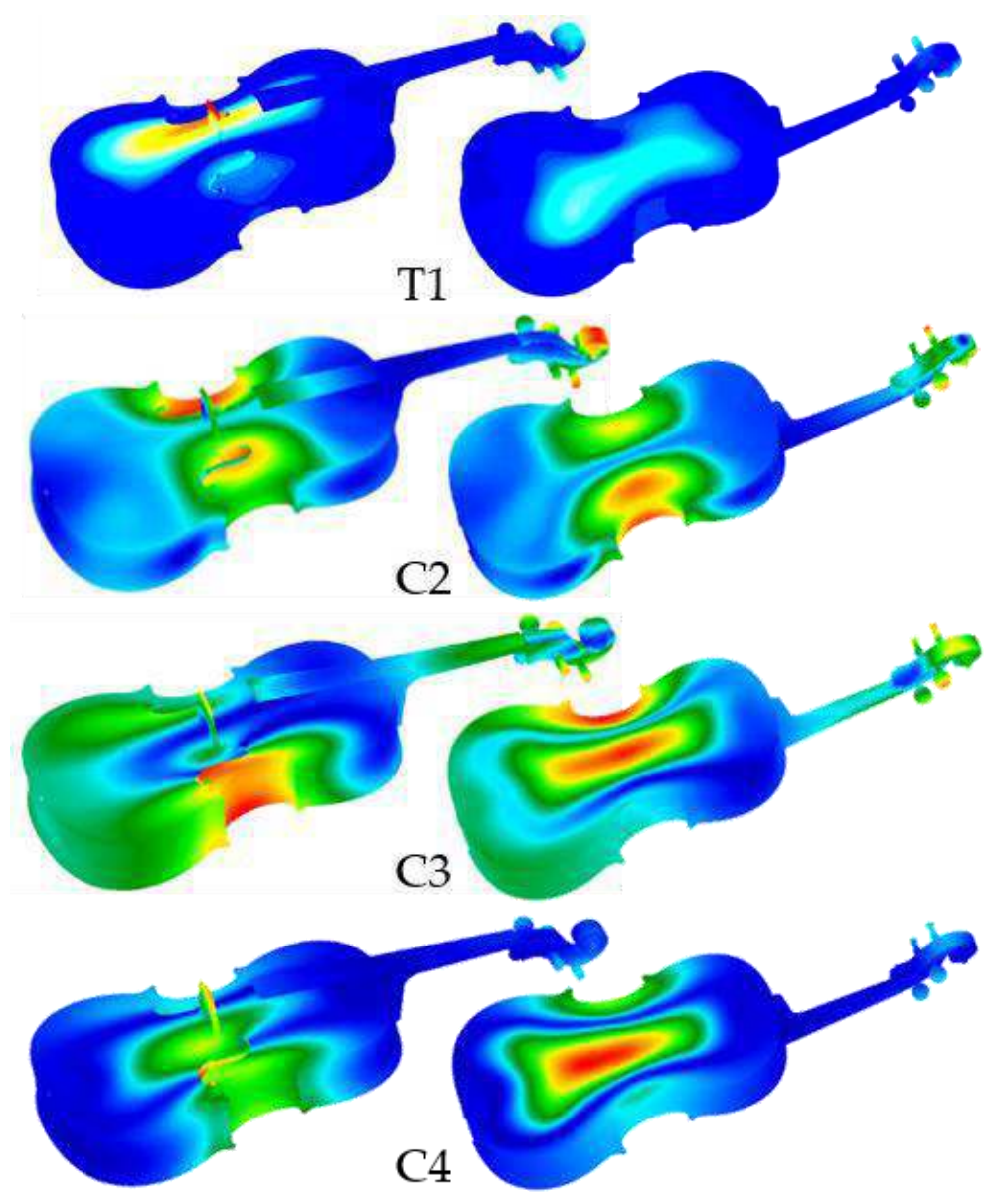

Figure 3: Normalized eigenvectors of the eigenmodes modes of interest (blue $=0$, red $=1$; left side: top view, right side: back view.

\begin{tabular}{|c|c|c|c|}
\hline Eigenmode & V1 & V2 & V2_2 \\
\hline T1 [Hz] & 191.3 & $179.4(-6.2 \%)$ & 179.4 \\
\hline C2 [Hz] & 179 & $164.2(-8.2 \%)$ & 164.5 \\
\hline C3 [Hz] & 207 & $222.1(+7.3 \%)$ & 221.8 \\
\hline C4 [Hz] & 213 & $212.2(-0.4 \%)$ & 212.1 \\
\hline
\end{tabular}

Table 2: eigenfrequencies of the first three modes of interest of the cello and their evolution for three difference cases: nominal model V1, modified model V2, and modified model V2 without repairs. Relative changes between V1 and V2 are given in brackets. 


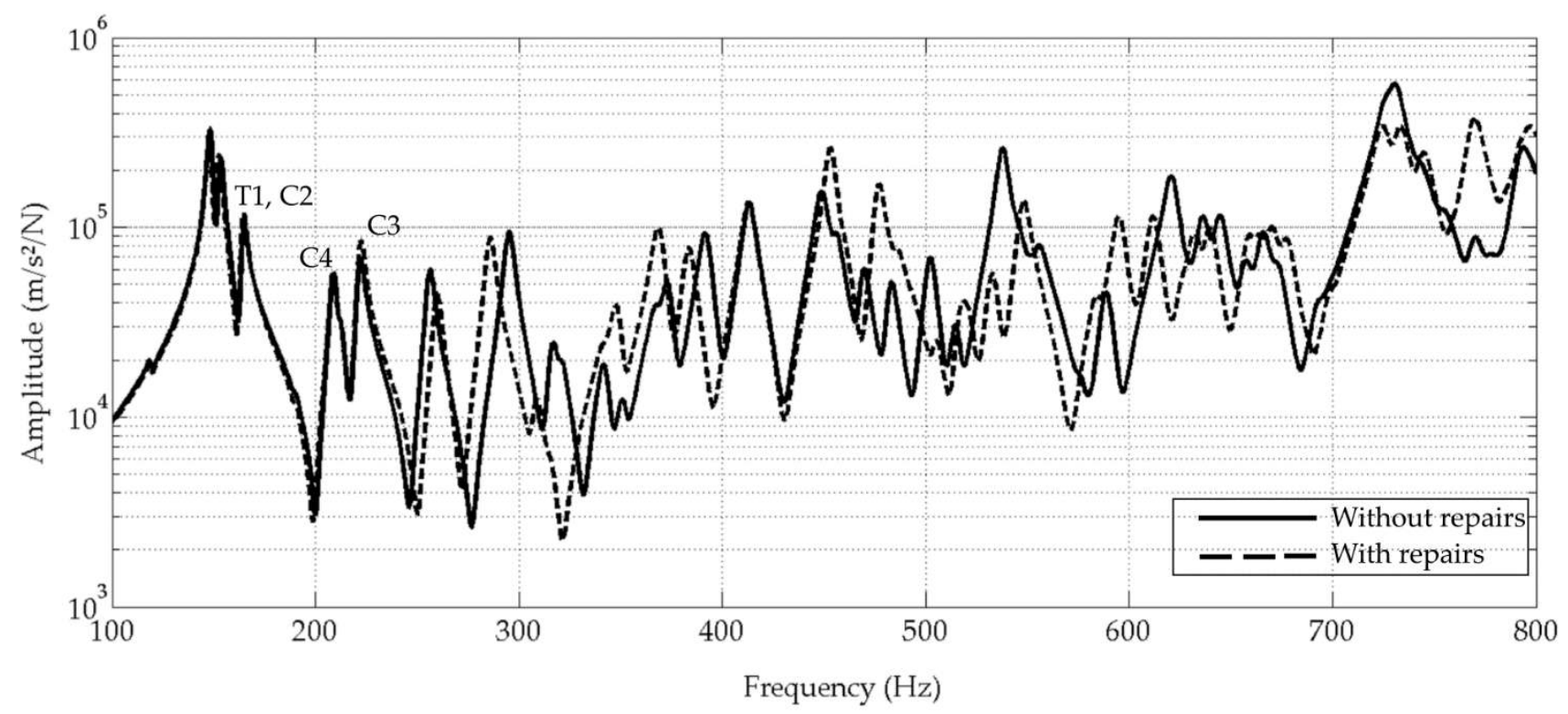

Figure 4: bridge admittance (acceleration) at the bridge with and without wedges and wormholes.

\section{CONCLUSION}

The numerical models created have highlighted two main facts. Firstly, the geometry accuracy is a key for the predictive capability of a cello, and geometrical properties like arch shape and height are essential for the precision of the model. Nowadays, such geometrical features are evaluated effectively with photogrammetry and CT scans means. Secondly, the effects of repairs like wedges and defaults like insect galleries can modeled with such models. The effects of these elements are important on the dynamical behavior of the cello, and this can be considered as an effective tool for more refined and dedicated studies, like the design of repairs wedges that would affect as lower as possible the behavior of the musical instruments, when such repairs are inevitable for the structural integrity of the instrument. In conclusion, this study shows that the numerical models can simulate the effect of restorers and instrument maker's decisions on the dynamical behavior, which can be a starting point for a decision support tool in both static and dynamical domains. The perspective proposed is to evaluate the impact of geometric and material uncertainties on the static response of the cello, when undergoing prestresses due to assembly and strings.

\section{REFERENCES}

[1] Knott, G. A., A Modal Analysis of the Violin Using MSC/NASTRAN and PATRAN, Naval Postgraduate School, 1987.

[2] Pyrkosz, M. A., Reverse Engineering the Structural and Acoustic Behavior of a Stradivari Violin, Dissertation, Michigan Technological University, 2013.

[3] Gough, C., Vibrational Modes of the Violin Family, In SMAC 13 Stockholm, 66-74, 2013.

[4] Viala, R., Placet, V., Cogan, S., Foltête, E., Model-based effects screening of stringed instruments, Conference Proceedings of the Society for Experimental Mechanics Series, 3, 151-157, 2016.

[5] Viala, R., Towards a model-based decision support tool for stringed musical instrument making, Dissertation, Université Bourgogne Franche-comté, 2018.

[6] Van den Bulcke, J., Van Loo, D., Dierick, M., Masschaele, B., Van Hoorebeke, L., Van Acker, J., Nondestructive research on wooden musical instruments: From macro- to microscale imaging with lab-based X-ray CT systems, Journal of Cultural Heritage, 27, S78-S87, 2015.

[7] Sirr, S., Waddle, J., X-ray CT Measurements of the Internal Corpus Volume and a New Soundpost- Corpus Volume Relationship for Stringed Instruments of the Violin Family, XXII (1), 1-12, 2009.

[8] Le conte, S., Vaiedelich S., François M.L.M., A Wood Viscoelasticity Measurement Technique and Applications to Musical Instruments: First Results, J. Violin Society Am, 21: 1-7, 2007. 
[9] Le Conte, S., Vaiedelich S., Thomas J.H., Muliava V., De Reyer D., Maurin E., Acoustic Emission to Detect Xylophagous Insects in Wooden Musical Instrument, Journal of Cultural Heritage 16 (3), Elsevier Masson SAS: 338-43, 2015.

[10] Fouilhé, E., Houssay, A., String “After-Length" and the Cello Tailpiece: Acoustics and Perception, Smac 13, April 2014, 0-5, 2013.

[11] Fouilhé, E., Goli, G., Houssay, A., Stoppani, G., Vibration modes of the cello tailpiece, Archives of Acoustics, 36(4), 713-726, 2011.

[12] Firth, I. A. N. M., Buchanan, J. M., The wolf in the cello, The Journal of the Acoustical Society of America, 457463, 1971.

[13] Wake, H. S., A 'Strad’ Mode, Wake publishing, Glastonbury, 1975.

[14] Viala, R., Placet, V., \& Cogan, S., Identification of the anisotropic elastic and damping properties of complex shape composite parts using an inverse method based on finite element model updating and 3D velocity fields measurements (FEMU-3DVF): Application to bio-based composite violin sounboard, Composites Part A: Applied Science and Manufacturing, 106, 91-103, 2018.

[15] Guitard, D., El Amri, F., Modèles prévisionnels de comportement élastique tridimensionnel pour les bois feuillus et les bois résineux, Annales Des Sciences Forestières, 44(3), 335-358, 1987.

[16] Allemang, R. J., Brown, D. L., A correlation coefficient for modal vector analysis, First International Modal Analysis Conference, 110-116, 1982.

[17] Zhang, A., Woodhouse, J., Stoppani, G., Motion of the cello bridge, The Journal of the Acoustical Society of America, 140(4), 2636-2645, 2016.

[18] Zhang, A., Woodhouse, J., Reliability of the input admittance of bowed-string instruments measured by the hammer method, The Journal of the Acoustical Society of America, 136(6), 3371-3381, 2014

[19] Askenfelt, A., Quarterly Progress and Status Report Eigenmodes and tone quality of the double bass, STL-QSPR, 23, 149-174, 1982. 